University of Nebraska - Lincoln

DigitalCommons@University of Nebraska - Lincoln

1987

\title{
A Climatology of Mean Monthly Snowfall for the Conterminous United States: Temporal and Spatial Patterns
}

John A. Harrington Jr.

New Mexico University

Randall S. Cerveny

Arizona State University

Kenneth F. Dewey

University of Nebraska - Lincoln, kdewey@unl.edu

Follow this and additional works at: https://digitalcommons.unl.edu/natrespapers

Part of the Natural Resources and Conservation Commons, Natural Resources Management and Policy Commons, and the Other Environmental Sciences Commons

Harrington, John A. Jr.; Cerveny, Randall S.; and Dewey, Kenneth F., "A Climatology of Mean Monthly Snowfall for the Conterminous United States: Temporal and Spatial Patterns" (1987). Papers in Natural Resources. 1078.

https://digitalcommons.unl.edu/natrespapers/1078

This Article is brought to you for free and open access by the Natural Resources, School of at DigitalCommons@University of Nebraska - Lincoln. It has been accepted for inclusion in Papers in Natural Resources by an authorized administrator of DigitalCommons@University of Nebraska - Lincoln. 


\title{
A Climatology of Mean Monthly Snowfall for the Conterminous United States: Temporal and Spatial Patterns
}

\author{
JOHN A. HARRINGTON, JR. \\ Department of Earth Sciences, New Mexico State University, Las Cruces, NM 88003
}

RANDALl S. CERVENY

Department of Geography, Arizona State University, Tempe, AZ 85287

KENNETH F. DEWEY

Climatology Program, Department of Geography, University of Nebraska-Lincoln, Lincoln, NE 68588

(Manuscript received 23 May 1986, in final form 24 January 1987)

\author{
ABSTRACT
}

\begin{abstract}
Mean monthly snowfall data for 216 stations across the conterminous United States were analyzed to produce a climatology that identifies statistical, spatial and intraseasonal aspects. Geographic variations in the length of the snowfall season are characterized using two statistics: the number of months of snow and the Snow Concentration Index (SCI).

The annual distribution of mean monthly snowfall is also examined using harmonic analysis. Snowfall across the conterminous United States generally peaks in February; earlier snowfall maxima are found in the Great Lakes area and in the Pacific Northwest, whereas late February or March maxima occur in the western High Plains. Stations with relatively high amounts of variance explained by the second harmonic indicate 1) areas with a short snowfall season such as the southeastern United States, or 2) areas with a long snowfall season that have a tendency toward a bimodal distribution.

A climatology of the changing monthly patterns of snowfall is identified through the mapping of individual station deviations from a national composite. This procedure produces contiguous regions that can be related to seasonal changes in the extent and positioning of the circumpolar vortex. The maps reveal that positive snowfall deviations predominate 1) in autumn in the northern and western Great Plains and the Rocky Mountains (with a full-latitude trough over the central United States and associated upslope precipitation); 2) in early winter in the Great Lakes (associated with lake-effect storms); 3) in late winter over the southern and western states (with a fully expanded circumpolar vortex); and 4) in spring in the western states (linked to seasonal changes in preferred locations of cyclogenesis and associated storm tracks).
\end{abstract}

\section{Introduction}

Snowfalls are meteorological events of considerable interest and, along with floods, hailstorms, tornadoes, or hurricanes, they can have pronounced economic effects. The costs of work cancellation, snow removal and other associated costs may be pronounced (Rooney, 1967). Most climatological studies of snow over the United States, however, have concentrated primarily on the timing and spatial distributions of snow cover and/or snow depth (Richter, 1960; Potter, 1965; Baldwin, 1974; Lamb, 1972; Dewey and Heim, 1982) and not on snowfall. Snow cover information has been summarized using weekly, monthly, and annual time scales and several investigations have demonstrated relationships between tropospheric circulation patterns and patterns of snow cover (Namias, 1960; Walsh et al., 1982; Heim and Dewey, 1984). The importance of snow cover information in both forecasting (Namias, 1985 ) and in general circulation modeling (Robock,
1980) has also been recognized for some time. Technological advancements in data collection have evolved to the point where satellite images now provide a basic data source for snow cover information (Wiesnet and Matson, 1979; Dewey and Heim, 1982).

Snowfall data differ significantly from snow cover data. A snowfall may be a single-day event, whereas most snow cover studies rely on the persistence of snow covered ground for several days. Thus, snow cover studies incorporate, in part, a low temperature persistence factor. Snowfall is, perhaps, more representative of the meteorological event. Hence, snowfall data also merit comprehensive climatological study.

Climatological studies have examined the synoptic patterns associated with 1) wave cyclone snowfalls (Goree and Younkin, 1966; Younkin, 1968; Browne and Younkin, 1970) and 2) lake-effect snows (Eichenlaub, 1970; Jiusto and Kaplan, 1972; Strommen and Harman, 1978; Dewey, 1979). These efforts were designed to improve 1) our understanding of the mech- 
anisms that generate a major snowfall and 2) the subsequent forecasting of these events. Existing climatologies have generally neglected study of spatial and intraseasonal variations in snowfall. Accordingly, this study provides a climatology of mean monthly snowfall over the conterminous United States from statistical and geographical frameworks.

\section{Data and methods}

Long-term mean monthly totals of snowfall (including ice pellets) were obtained from Comparative Climatic Data for the United States through 1980 (NOAA, 1981). Data for 216 stations across the conterminous United States that had at least 1 month with a mean during the period of record that was greater than a trace were used in this analysis. Because length of the data record varies considerably in this dataset, only stations with at least a $10 \mathrm{yr}$ data record were included. Using an initial data file consisting of 216 stations with 12 monthly mean snowfall totals, several descriptive statistics were calculated for each station. These statistics included the number of months of measurable snowfall and an index of snowfall concentration.

Harmonic analysis was used as an investigative tool for studying the cyclical nature of the annual snowfall time series. Phase angles, variances, and amplitudes for the first and second harmonics are reported.

Intraseasonal variations were examined through analysis of the geographic patterns of monthly percentage contribution to the station annual snowfall total. Mean monthly snowfall totals for all 216 stations were averaged to determine a composite, or "normal," snowfall profile for the conterminous United States. Next, monthly percentage contributions to the composite total were calculated; similar monthly percentage contributions were determined for each station. Deviations from the composite were then calculated for each station for each month of the year. Resultant monthly deviation statistics provide information on how an individual station's snowfall distribution differs from the composite. Geographic analyses of these station deviations were performed for each month from October through May.

\section{Temporal and geographic variations in the annual cycle}

Snowfall across the conterminous United States has a marked annual cycle that generally reaches a maximum during the coldest months of the year. However, significant geographic variations occur in the length of the snow season. In this study, the number of months of snow and an index of seasonal concentration are used to help characterize the length of the season.

The number of months of measurable mean monthly snowfall (Fig. 1) varies from zero for stations in southern California, southern Texas, and most of
Florida to eleven months for Stampede Pass, Washington and Mt. Washington, New Hampshire. Since a nonzero monthly mean can be produced by snowfall occurrences in a small number of years, this statistic should be interpreted as an indication of the length of the season of possible snowfall. The map patterns suggest that three factors (latitude, elevation, and continentality) combine to influence the length of the snowfall season. Areas that have a possible snowfall season of eight months or more are found throughout the mountainous areas of the west, the northern part of the Upper Midwest, and in northern New England. Areas with less than a 4-month season of potential snowfall are found in central and southern California, southwestern Arizona, and along the Gulf coastal states.

Due to difficulties in interpreting the meaning of statistics and mapped patterns generated for stations with short snowfall seasons, our analysis concentrated on those areas with a four month or longer snowfall season. Consequently, map products indicate statistical and spatial patterns for those areas with stations with four or more months of measurable mean snowfall.

The length of the snow season and the evenness of the annual distribution are addressed through calculation and analysis of a Snow Concentration Index (SCI); this concept and the mathematical equation for the index were developed after Oliver's (1980) analysis of monthly precipitation distributions. Mathematically, the $\mathrm{SCI}$ is expressed as

$$
\mathrm{SCI}=100\left[\sum_{i=1}^{N} x^{2} /\left(\sum_{i=1}^{N} x\right)^{2}\right]
$$

where $x$ is the mean monthly snowfall and $N$ is the number of months (12). In contrast to other statistical measures of variation, SCI is a nondimensional, bounded index. Values of the index range from 8.33 , for equal precipitation totals in all 12 months, to 100.0 for a 1-month snowfall season. Values of the SCI are inversely related to the number of months of snowfall (correlation coefficient $=-0.77$ ). Lowest $\mathrm{SCI}$ values (indicating the longest snowfall seasons) occur in a large area that extends south and westward from the western Great Lakes to cover the Rocky Mountains and some sections of the intermountain West (Fig. 2). SCI values tend to increase in both a southeasterly and a westerly direction from this core area.

\section{Harmonic analysis of the annual cycle}

Although snowfall is predominantly a winter season phenomenon, stations across the contiguous United States do not display the same temporal characteristics. Suitability of harmonic analysis for climatic investigations has been well established (Craddock, 1956; Horn and Bryson, 1960; Fitzpatrick et al., 1966; Balling and Cerveny, 1983, 1984). In harmonic analysis, each station's annual distribution is represented as a number 


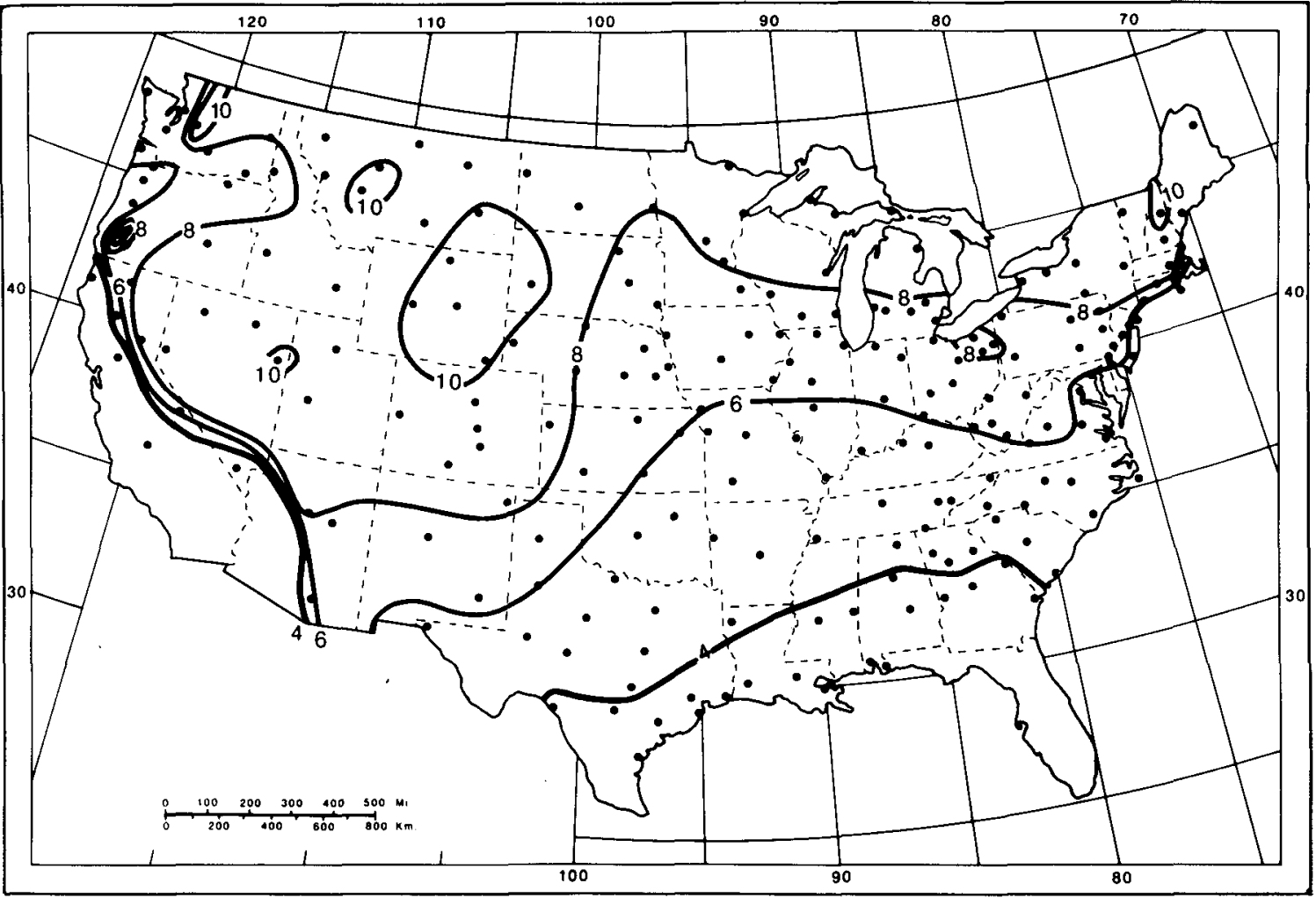

FIG. 1. Number of months of measurable snowfall and the locations of the 216 stations used in this study.

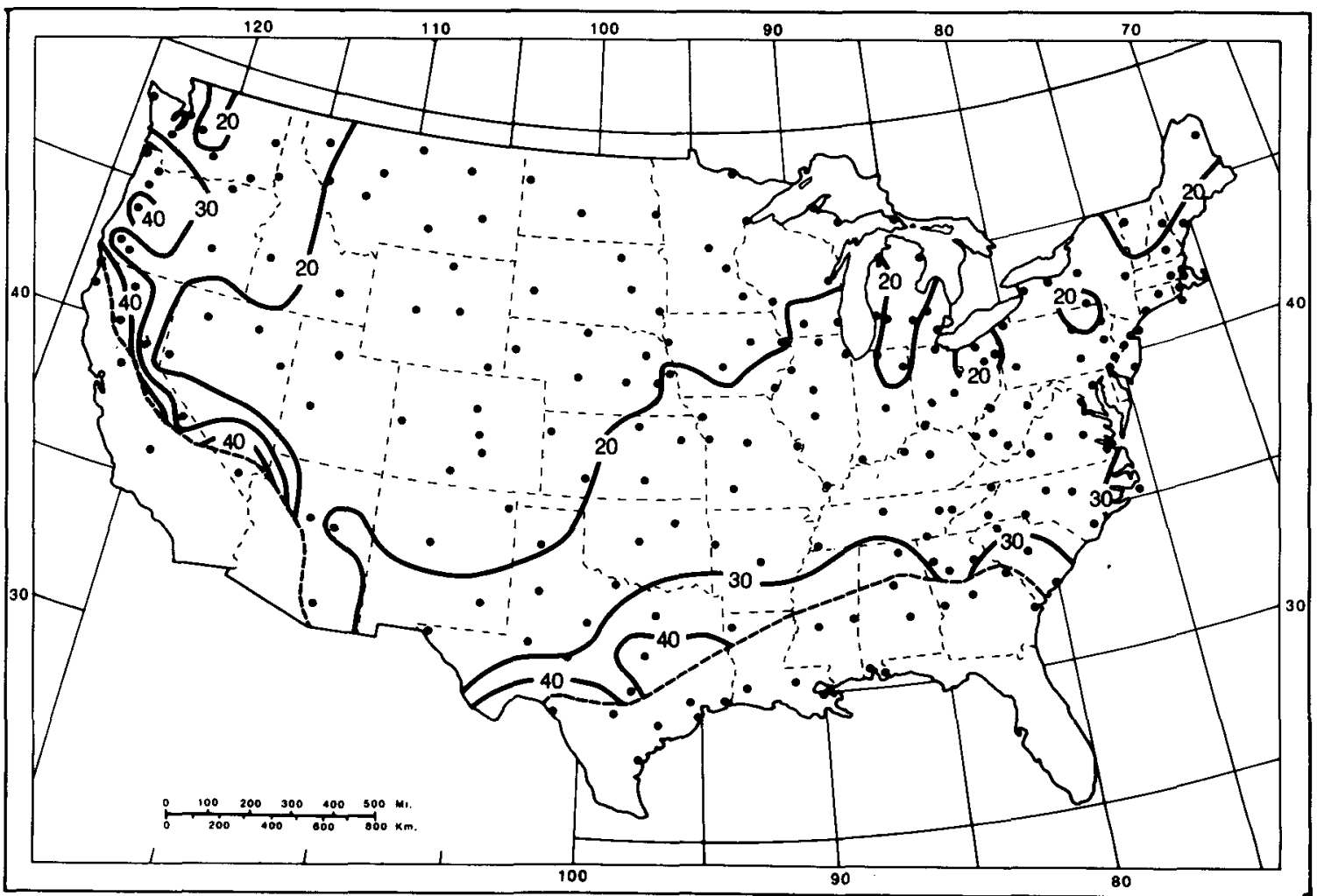

FIG. 2. Snow Concentration Index. 
of statistically independent sinusoidal components, which can be individually analyzed and mapped.

Harmonic analysis determines how well a temporal distribution matches a sinusoidal cycle. The first harmonic compares the given distribution with a sinusoid curve of one cycle per period (one maximum and one minimum spaced 6 months apart). Following the subtraction of the annual cycle from the distribution, the biannual variance structures are represented by the second harmonic, which displays two equally spaced maxima and minima. The generalized form of harmonic analysis is

$$
\hat{x}=\bar{x}+\sum_{r=1}^{N / 2} A_{r} \cos \left(r \theta-\Phi_{r}\right)
$$

where $\hat{x}$ is the estimated monthly value of $x, \bar{x}$ the mean annual snowfall, $N$ the number of observations at each station (12 months), $A_{r}$ the amplitude of each harmonic wave of frequency $r, \theta$ is $2 \pi t / p$ where $t$ is the time in months and $p$ is the fundamental period (12 months), and $\Phi_{r}$ the phase angle of the wave. In order to account for all the variance in a particular distribution, $p / 2$ harmonics are required (six harmonics for monthly data). With seasonal phenomena, the amount of variance explained by the higher harmonics (i.e., the third, fourth, fifth, and sixth) is quite low and often not statistically significant (Brooks and Carruthers, 1953).

Three statistics are reported for the analysis of each harmonic: the variance explained, the amplitude, and the phase angle. Amplitude is a measure of the magnitude of the difference between the peak and the trough. In the case of the first harmonic, it is a function of the numerical difference between the lowest and heaviest snowfall totals that are approximately six months apart. The phase angle indicates the time within the period when the relative maxima and minima occur. Variance explained for each station for each harmonic suggests the importance of circulation and synoptic influences on snowfall events. The degree to which the data for a given station are best represented by the annual expansion and contraction of the circumpolar vortex, is present in the first harmonic data. The second harmonic provides an indication of stations which have a more extensive snowfall season and a tendency toward a bimodal distribution.

Across the conterminous United States, the variance explained by the first harmonic (Fig. 3) ranges from over $96 \%$ at Miles City, Montana to under $50 \%$ for stations,. such as those in the southeastern United States, that have a relatively short snowfall season (Fig. 1). Stations at high elevations, areas in northern New England, and locations in the northern Great Plains show the highest explained variance. Lower values of explained variance are characteristic of the Pacific Northwest, the Southeast, and sections of Wyoming.

Timing of the snowfall maxima and minima are in- dicated by the first harmonic phase angle (Fig. 4). Dates shown on Fig. 4 correspond with the maxima; by definition, the minima have the same spatial pattern and occur six months later. Across the majority of the conterminous United States, snowfall peaks in February. Areas with earlier snowfall maxima are found in the Pacific Northwest and around the Great Lakes. Late February and March snowfall maxima are characteristic of stations in the western High Plains.

Amplitude of the first harmonic (Fig. 5) maximizes in areas of highest mean annual snowfall totals. These areas include the high elevation stations and stations in the Great Lakes snowbelt. Lowest values occur across the southern United States.

The pattern of variance explained by the second harmonic (Fig. 6), or a two-peaked distribution, contrasts strongly with that of the first harmonic (Fig. 3). Areas with relatively high amounts of variance explained by the second harmonic fall into three groups. For stations such as Lander, Wyoming the two peaks straddle a midwinter relative minimum and indicate an extended snowfall season. For areas to the lee of the Great Lakes, this statistic indicates the influence of the 3 to 4 month lake-effect snow season. In the southeastern United States, the relatively high values of explained variance associated with the second harmonic are indicative of a shorter, single-peaked snowfall season.

These interpretations of the results of the second harmonic are supported by the phase angle data (Fig. 7). Areas in the southeastern United States and the Great Lakes have maxima that coincide with the first harmonic; hence, the two sine wave patterns superimpose maxima in early February. For the western High Plains and high elevation areas in northern New England (i.e., Mt. Washington), the situation is different. The two peaks of the second harmonic are in late March/early April and late September/early October and indicate a lengthy snowfall season.

Geographic analysis of the amplitude of the second harmonic indicates two areas with relative maxima: one is downwind from the Great Lakes, while the other is in the western High Plains (Fig. 8). For the stations in the Great Lakes snowbelt, these high amplitudes indicate a relatively excessive amount of midwinter snowfall compared with most stations across the United States. High amplitudes in the western High Plains suggest that this region has a tendency toward a bimodal mean monthly snowfall profile, with higher snowfall totals near the beginning and end of the snowfall season rather than in the middle of winter.

In order to better identify those regions that experienced prolonged snowfall seasons, the time difference in months between the phase angles for the first and second harmonics was determined. This statistic was generated by subtracting the time of the peak of the first harmonic from the time of the first peak of the second harmonic. Stations with the largest deviations 


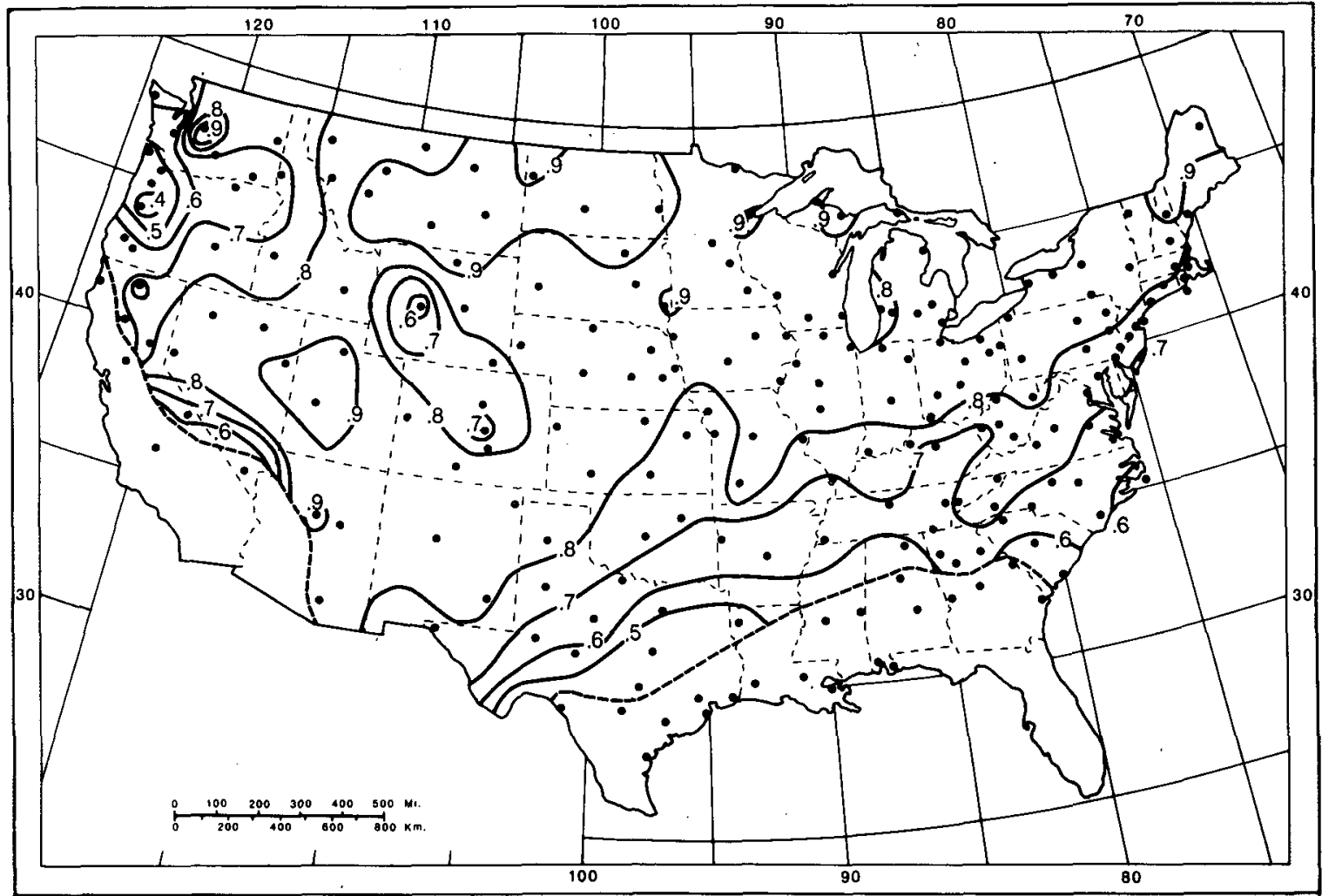

FIG. 3. First harmonic-variance (percentage expressed as a decimal).

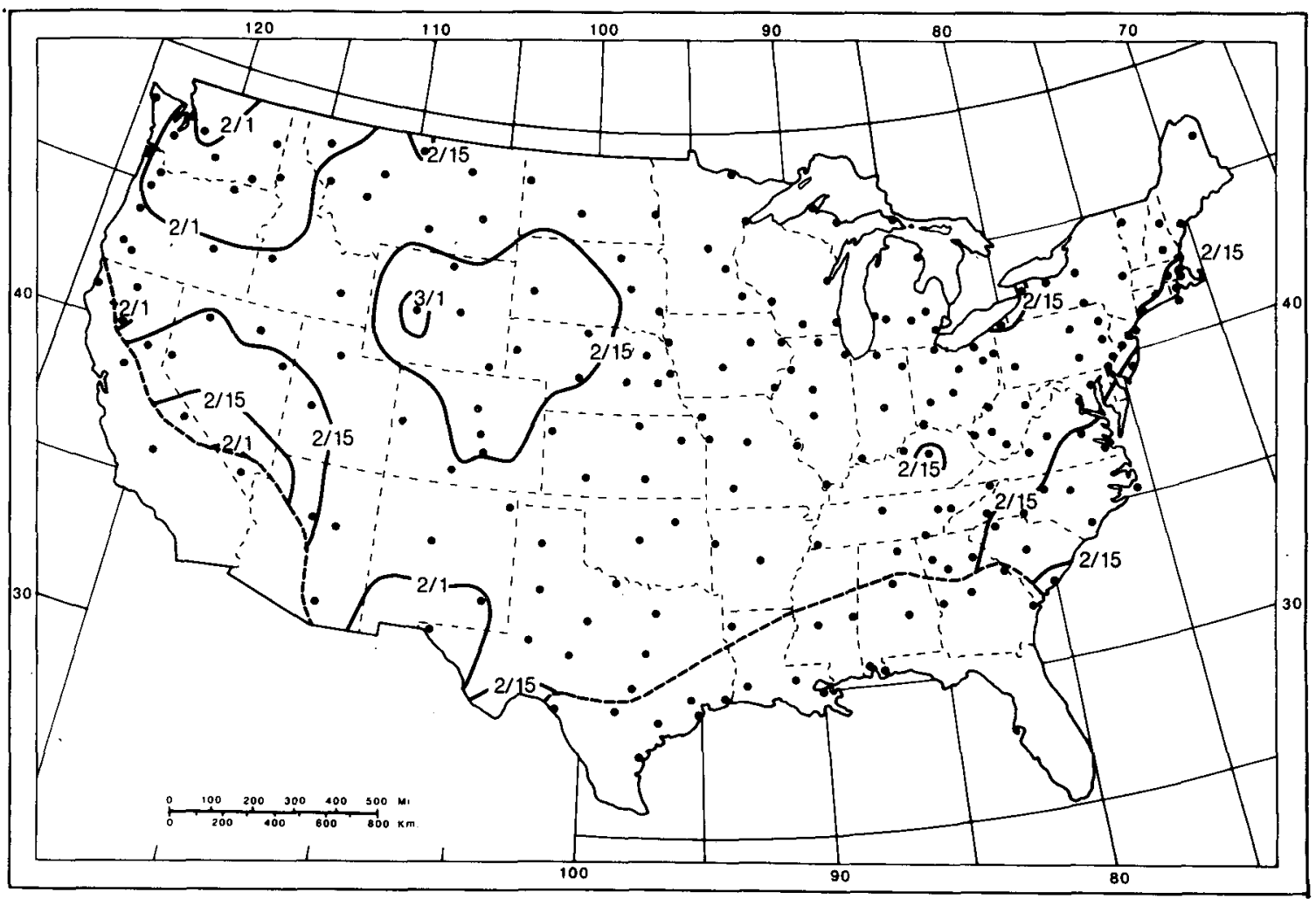

FIG. 4. First harmonic-phase angle (month/day). 


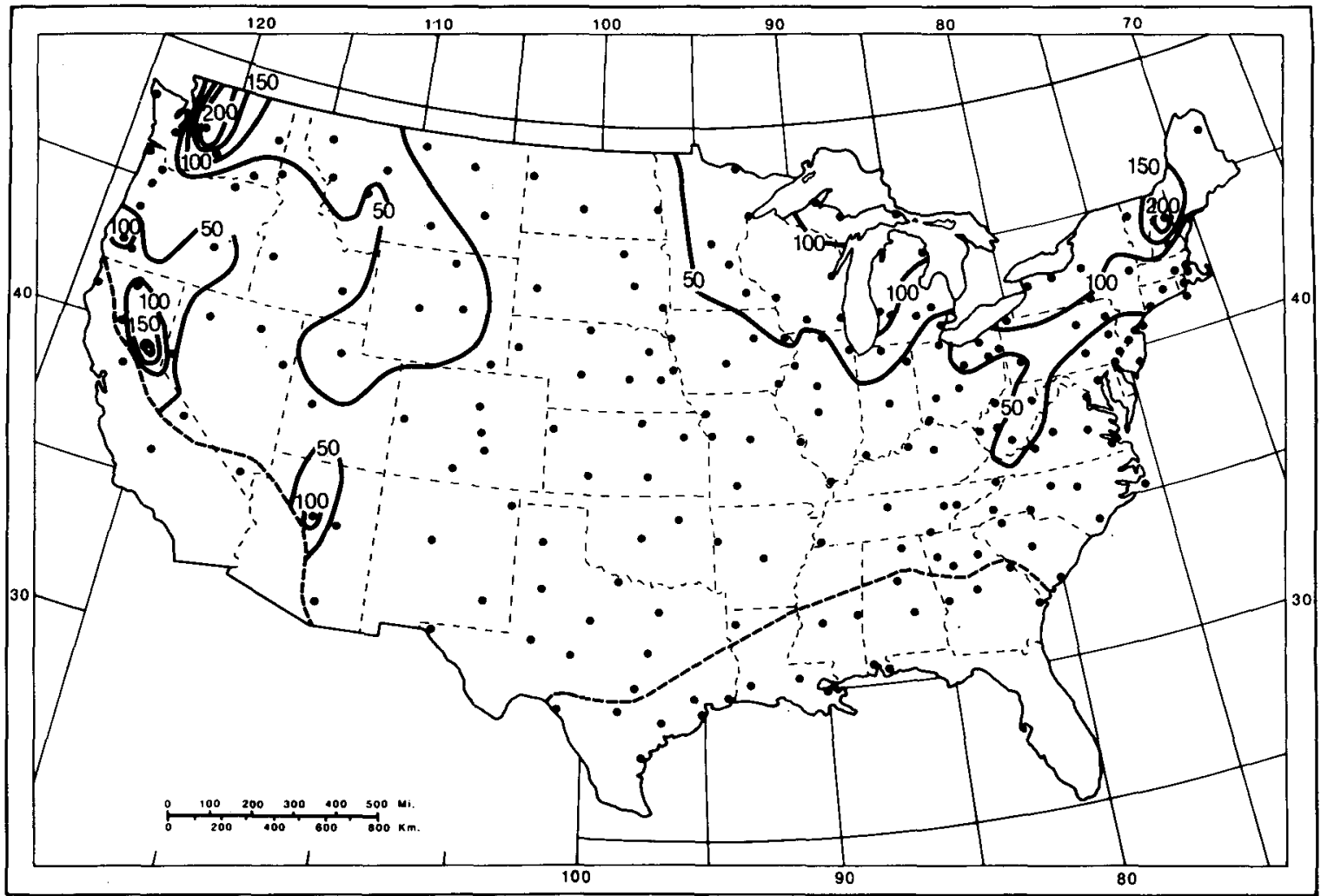

FIG. 5. First harmonic-amplitude (inches).

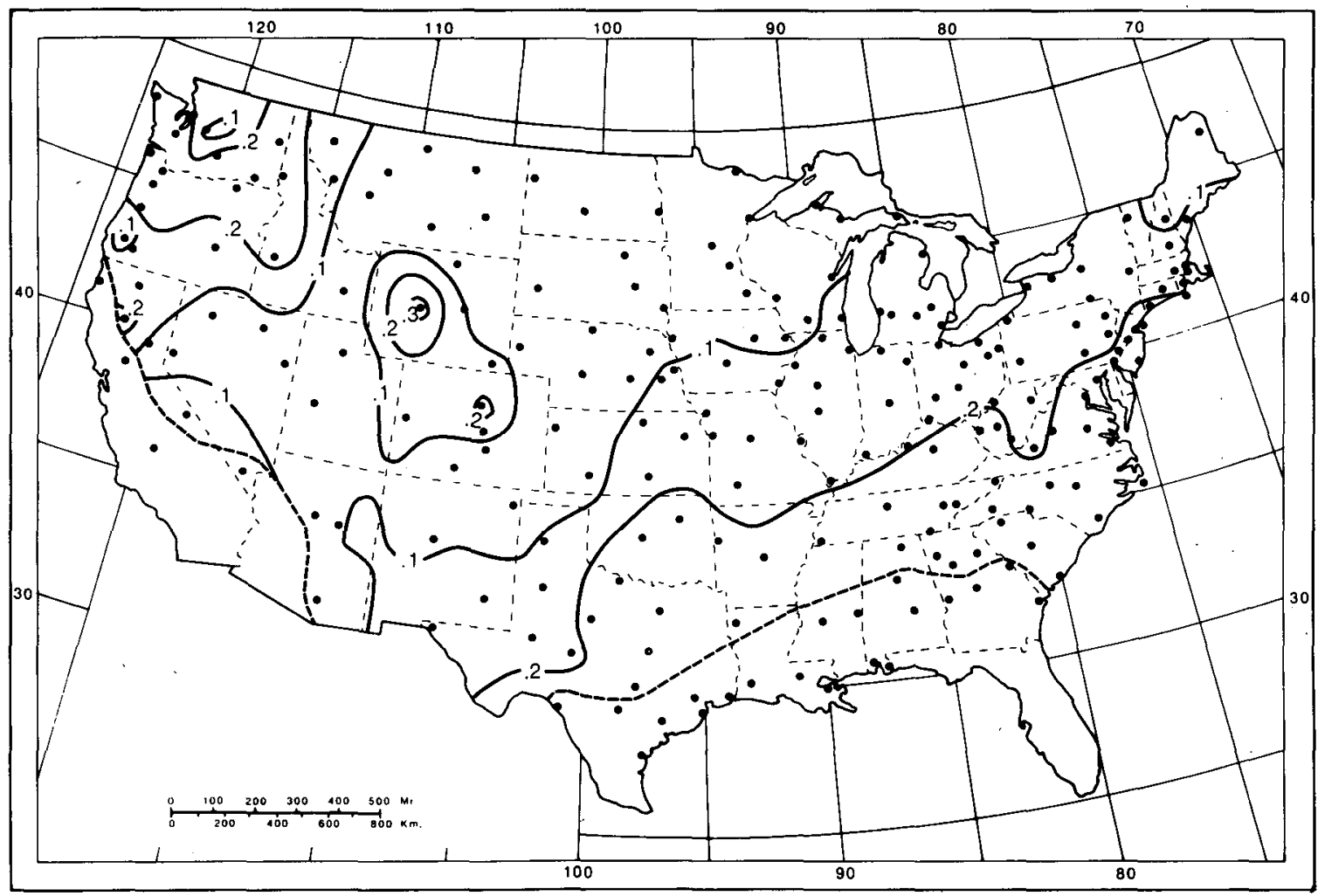

FIG. 6. Second harmonic-variance (percentage expressed as a decimal). 


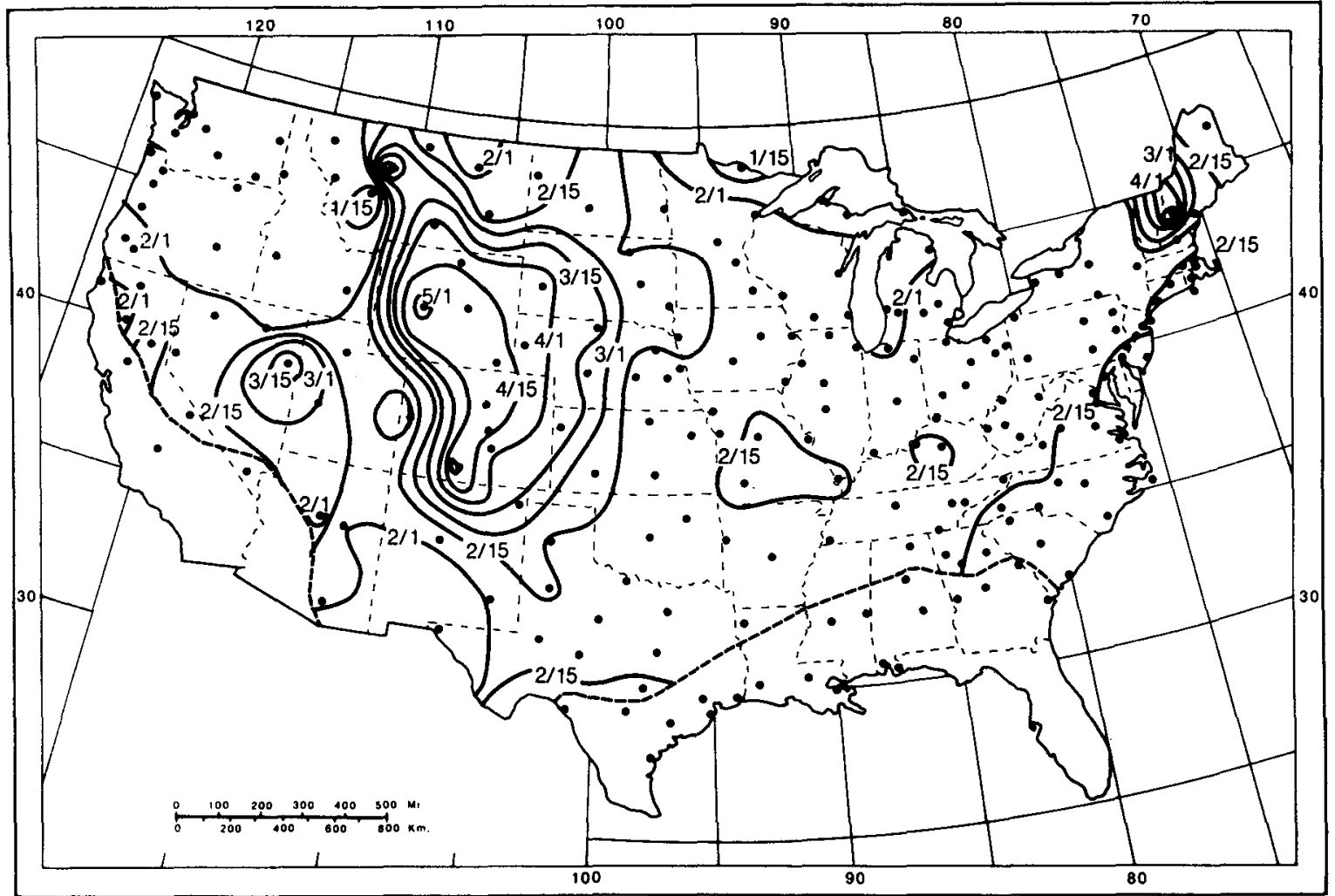

FIG. 7. Second harmonic-phase angle (month/day).

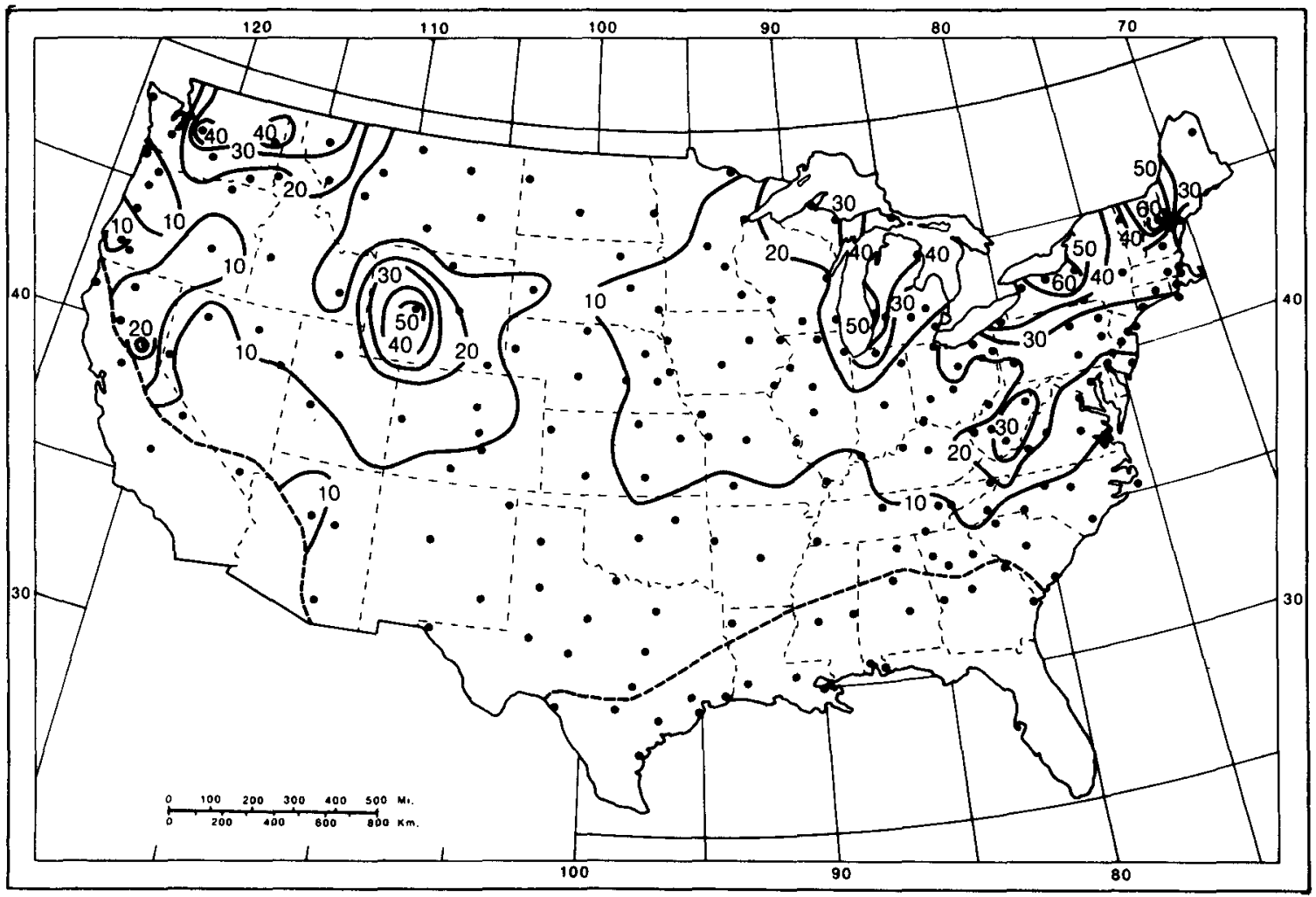

FIG. 8. Second harmonic-amplitude (inches). 


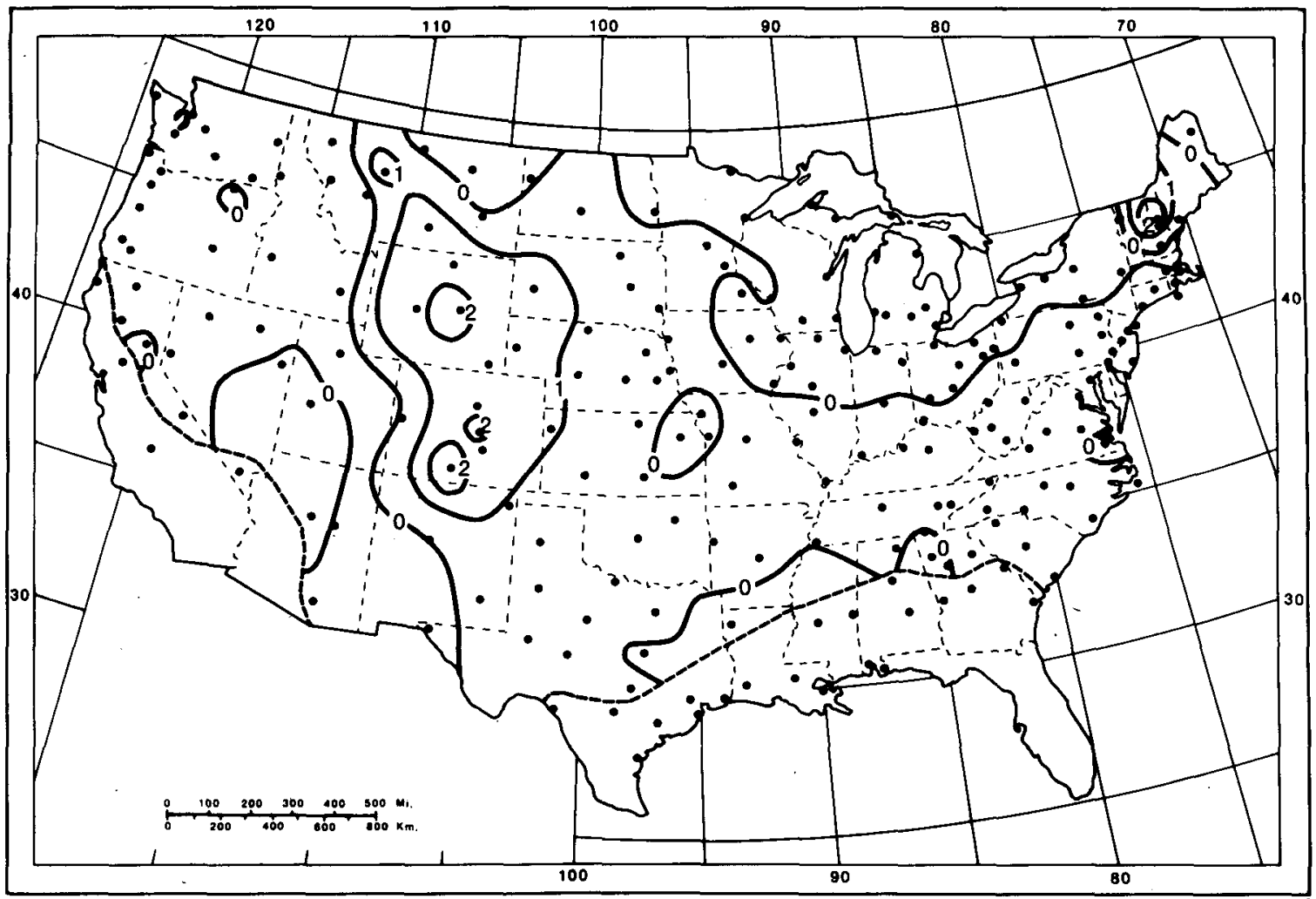

FIG. 9. Phase angle difference (in months). See text for discussion of calculation procedure.

from zero indicate those areas that combine a tendency toward a bimodal distribution with a relatively more extensive snowfall season (Fig. 9). High elevation stations in New England (i.e., Mt. Washington) and in the High Plains areas of Colorado and Wyoming have these characteristics.

The total amount of variance explained by the first two harmonics is generally above $80 \%$ for most stations with 4 or more months of snowfall. This suggests that a relatively simple statistical model consisting of one or two sinusoidal curves can be used to fit the climatology of snowfall events across the majority of the United States.

\section{Intraseasonal variation: Monthly percentages. of station total}

\section{a. Overview}

Due to the large variations in the magnitude of mean monthly snowfall totals for the conterminous United States, regional evaluation of monthly or seasonal snowfall concentration is difficult. One method for eliminating magnitude influences from a dataset is to determine monthly percentages of the annual total. In this investigation, an individual station's percentage of annual snowfall for each month was compared with a similar monthly statistic computed for a national composite of all 216 stations. This technique allows direct comparison between stations with differing snowfall magnitudes.

It should be noted that the deviation from a national composite monthly percentage statistic does not provide the same information as monthly snowfall total. Percentage calculation has standardized the data and subsequent determination of the deviation from a national composite has provided a statistic that can be used to examine the local variation in the timing of snowfall. When individual station deviations in monthly snowfall percentage are mapped, contiguous regions are created that can be related to seasonal changes in the circumpolar vortex and other measures of the climatic system.

\section{b. Autumn (October and November)}

The largest contiguous region demonstrating an above average percentage of snowfall in the month of October stretches from northern Minnesota southwestward across the central Great Plains to the southern Rocky Mountains and then northward to the Canadian border (Fig. 10): Three small areas also demonstrate a positive deviation for October snowfall: northern New England, Michigan's Upper Peninsula, and high elevations in the Cascade Mountains of Washington State. These three locations are, at times, north of the Polar Front Jet and its traveling cyclones, increasing the possibility of frozen precipitation. 


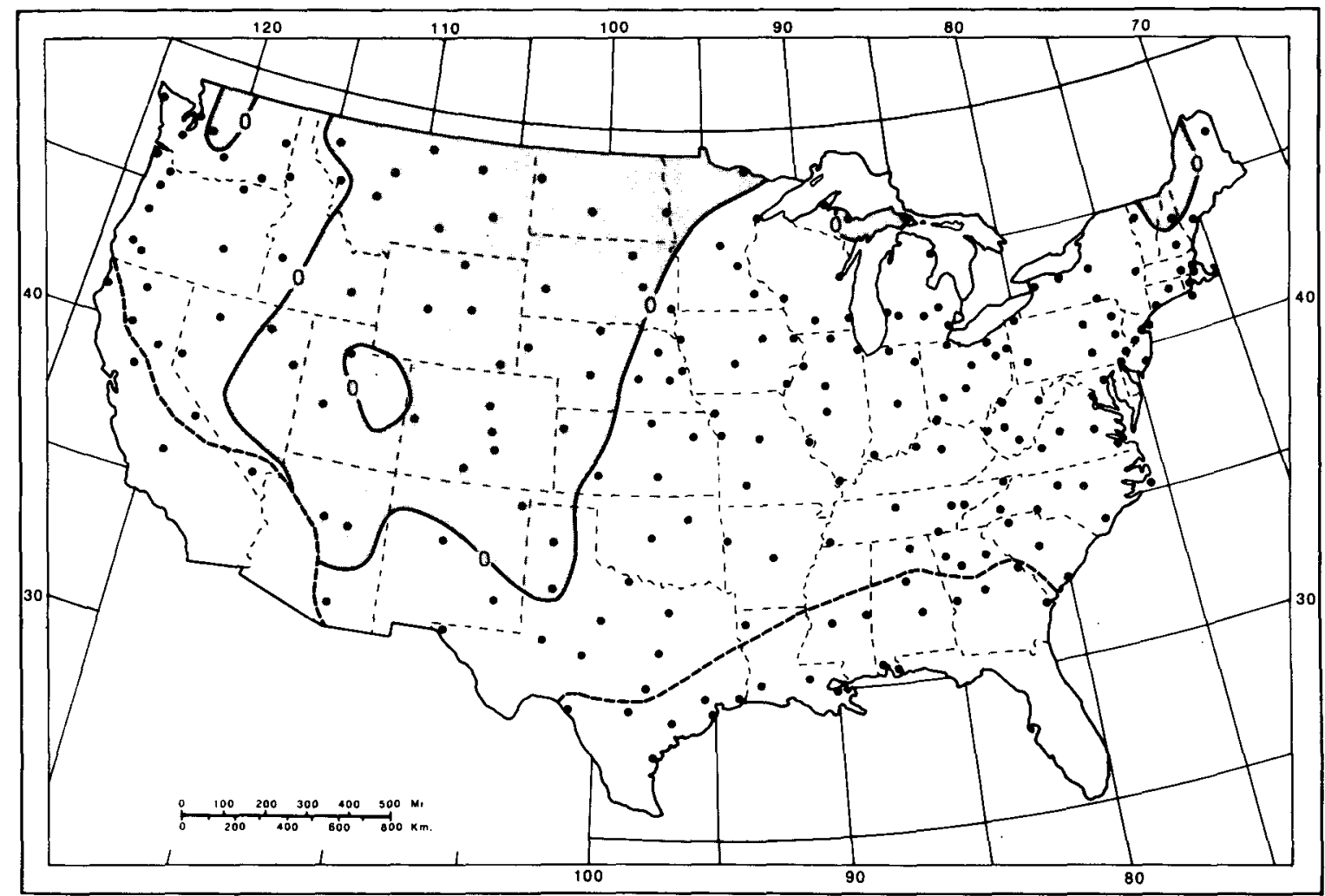

FIG. 10. October percentage deviations from the national composite. Shaded areas have a greater monthly percentage of their annual snowfall total than the national composite.

By November, the midcontinent region of positive deviations in snowfall percentage (Fig. 11), has expanded to cover areas further south and east across the Great Plains. The broad area stretching from the central Midwest southward to the Gulf of Mexico, as well as eastward to the Atlantic Ocean, has not yet entered its snowfall season fully, as evidenced by these areas having near-zero, or negative, deviation values. Two small regions of positive deviations are evident on the November map: the Ozark Mountains area (which may be related to the relatively high elevation of Springfield, Missouri in comparison with its surrounding stations) and a belt to the lee of the western and central Great Lakes, associated with lake-effect storms.

Meteorological and climatological aspects of lakeeffect snowfall can be used as an explanation for the existence of positive November snowfall deviations in the Great Lakes region. Many researchers (e.g. Falconer et al., 1964; Eichenlaub, 1970; Changnon and Jones, 1972; Jiusto and Kaplan, 1972; Dewey, 1979; Hjelmfelt and Braham, 1983) have demonstrated that the maximum lake-effect influence occurs during the months of November and December. Ice cover is extremely limited throughout the Great Lakes during this time of year. In addition, the lakes are relatively warm in late autumn and early winter, providing a large contrast to the thermal properties of Polar and Arctic airstreams.
The midcontinent region of positive snowfall deviations, evident in both October and November, is produced by snowfalls that occur in conjunction with an amplified flow that exhibits a deep trough in the area (Fawcett and Saylor, 1965; Goree and Younkin, 1966). Normally, trough development in October occurs more frequently in the Gulf of Alaska (Stark, 1965), with a tendency for near zonal flow across the northern tier of states (Harman, 1982). Wahl (1954) has suggested that a circulation readjustment, characteristic of late October, results in 1) a southward shift in the cyclonic storm track and 2) the first occurrence of cold season snowfalls across the northern Great Plains. As autumn progresses, climatological means indicate ridge development in the Canadian Rockies and enhancement of a downstream trough over the eastern United States (Stark, 1965). Departures from the climatological mean are typical of transition seasons (Namias, 1953; Stark, 1965) and can produce a progression of long wave troughs across the North American continent (Harman et al., 1980). Thus, the circulation regime related to the production of early season snowfalls across the midcontinent - a full-latitude trough covering western and central areas-is an unusual, but not unexpected, pattern.

Cyclogenesis in Colorado (or perhaps Wyoming in late September and October), which results in the possibility of frozen precipitation to the northwest of the 


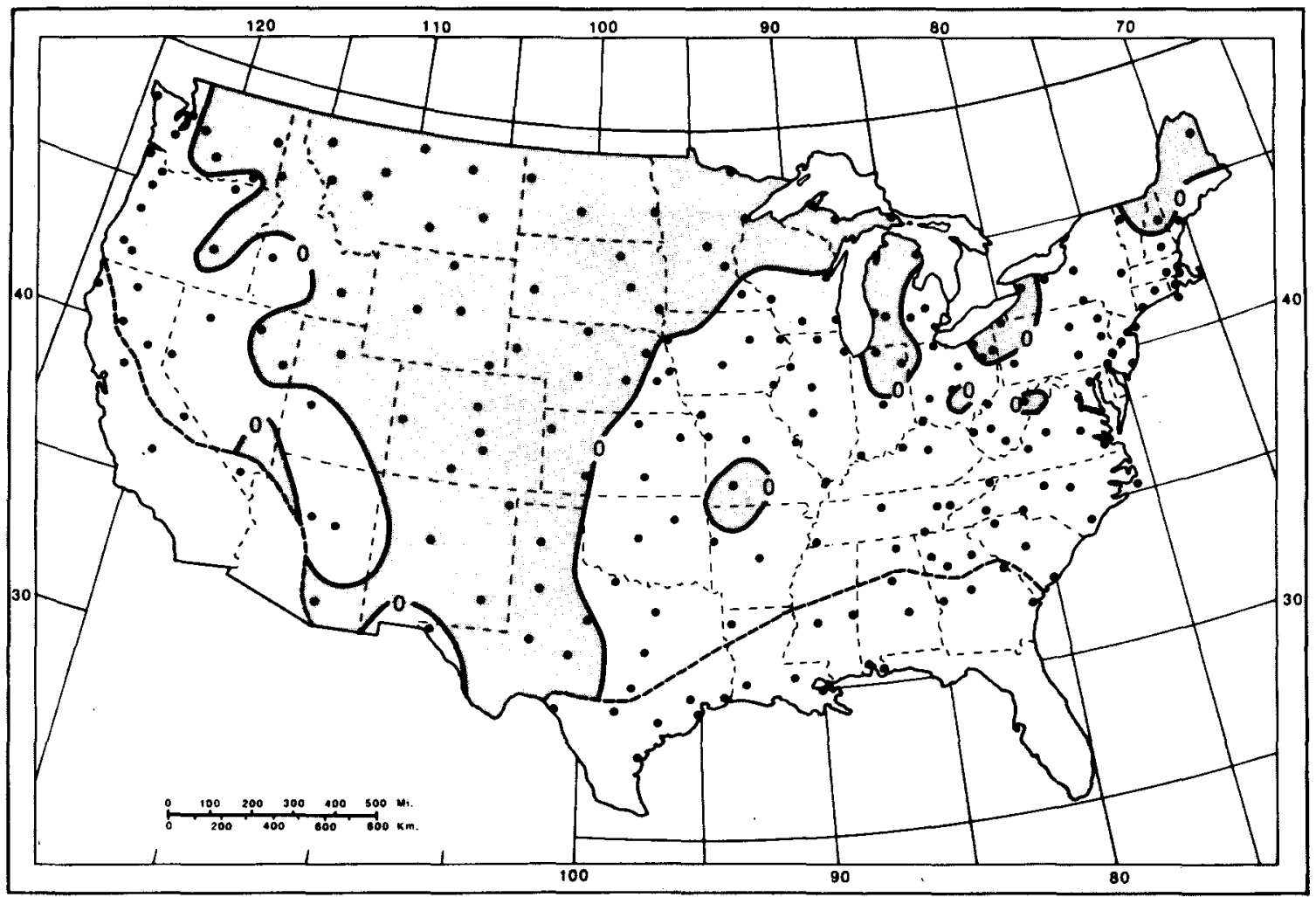

Fig. 11. As in Fig. 10, except for November.

storm track, is common with midcontinent troughs (Fawcett and Saylor, 1965; Goree and Younkin, 1966). With a full-latitude trough in the central United States, a considerable amount of moisture can be advected northward from the western Gulf of Mexico (Harman, 1982). Thus, individual storm snowfall totals may be large in the High Plains and Rocky Mountains and this snowfall is linked to upslope precipitation mechanisms (Klein, 1948; Laird and Dickey, 1953; Klein, 1963; Boatman and Reinking, 1984).

\section{c. Early winter (December and January)}

The mapped pattern of December snowfall anomalies (Fig. 12) has an area of positive snowfall deviations surrounding the entire Great Lakes; a second region of positive deviations extends in a belt from the Pacific Northwest to New Mexico and west Texas. The snowfall deviations from a national composite have decreased across the northern and western Great Plains and northern Rocky Mountains, indicative of the increased frequency of drier polar high pressure systems.

Negative percentage deviations continue in January for areas throughout the northern and western Great Plains as well as the central and northern Rockies (Fig. 13). These areas, which have a tendency for a midseason depression in the annual snowfall curve, have their largest negative deviations of the snowfall season. Large positive deviations characterize the short (and hence highly concentrated) snowfall season for a broad area from the south central Great Plains to the Middle Atlantic states. Positive deviations are also found along the Pacific coast and in the intermountain West.

Circulation readjustments are characteristic features of the December synoptic climatology (Dickson, 1967), with December and January characterized by a continuing expansion of the circumpolar vortex. The effects of thermal and dynamic influences on the position of wave features in the westerlies combine to produce a modal long-wave pattern with a ridge over the mountains of western North America and a trough above the strong baroclinic zone along the east coast. These changes are accompanied by a resultant southward shift in the position of the Polar Front Jet and the associated surface storm tracks (Klein, 1957; Whittaker and Horn, 1981).

Alberta and Colorado are cyclogenesis regions for the two most important storm tracks that affect the eastern United States during early winter. As these storms progress toward the East Coast, cold air advection behind the surface low can be pronounced and the lake-effect snow production mechanism significantly enhances snowfall totals. The track of Colorado cyclones is evident in the positive snowfall deviations that extend northeastward from the south central Great Plains into the eastern United States. Polar anticyclones 


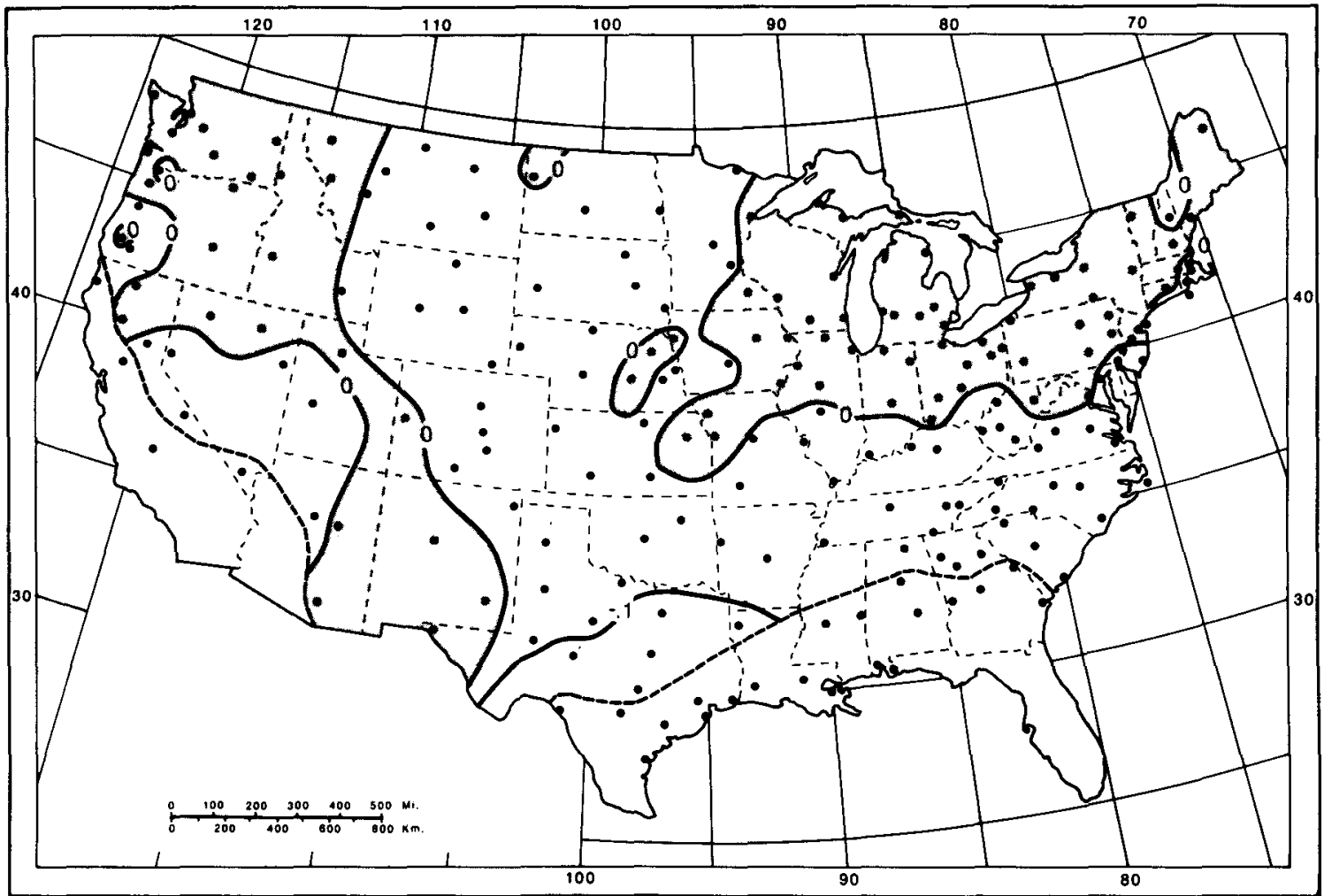

FIG. 12. As in Fig. 10, except for December.

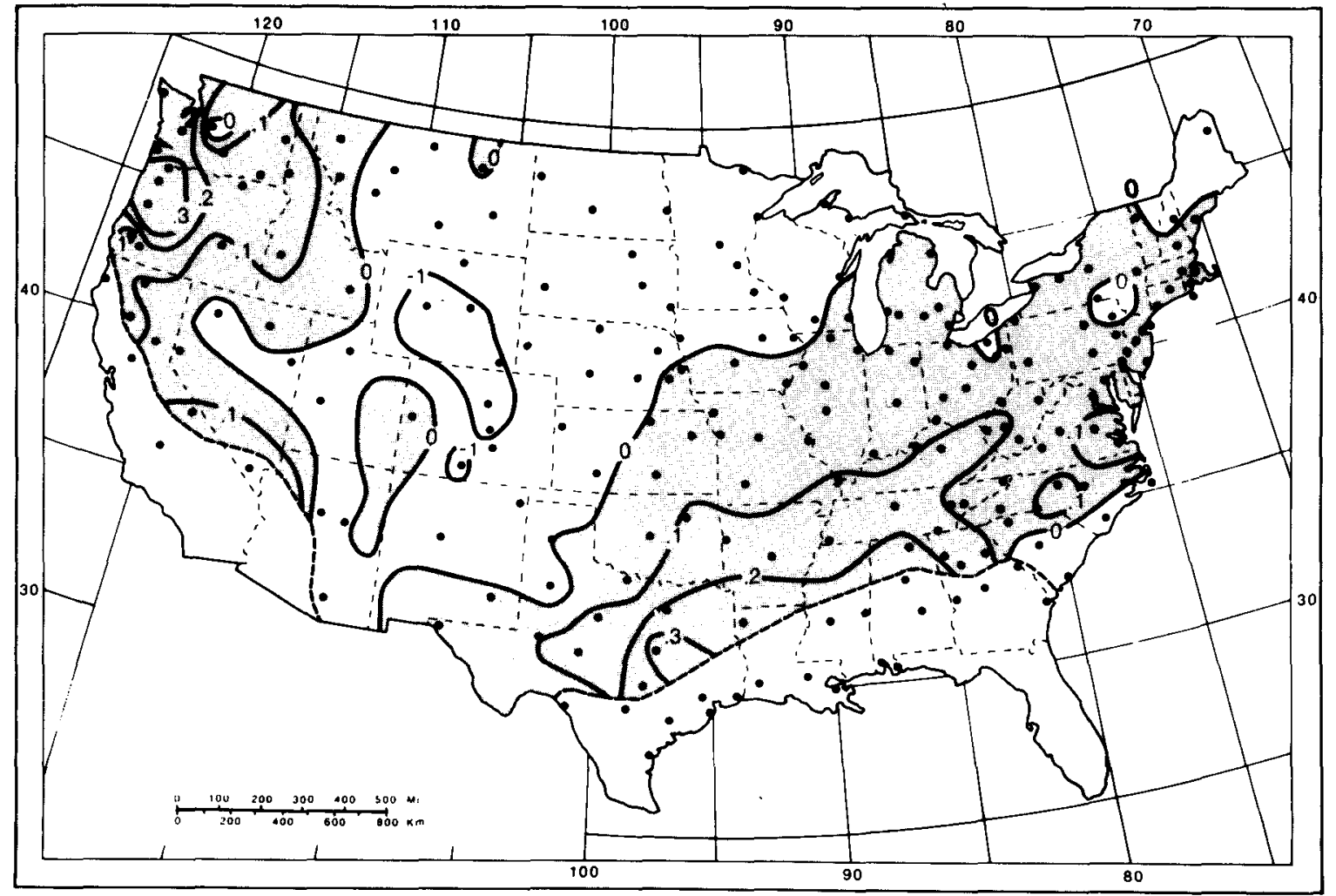

FIG. 13. As in Fig. 10, except for January. 


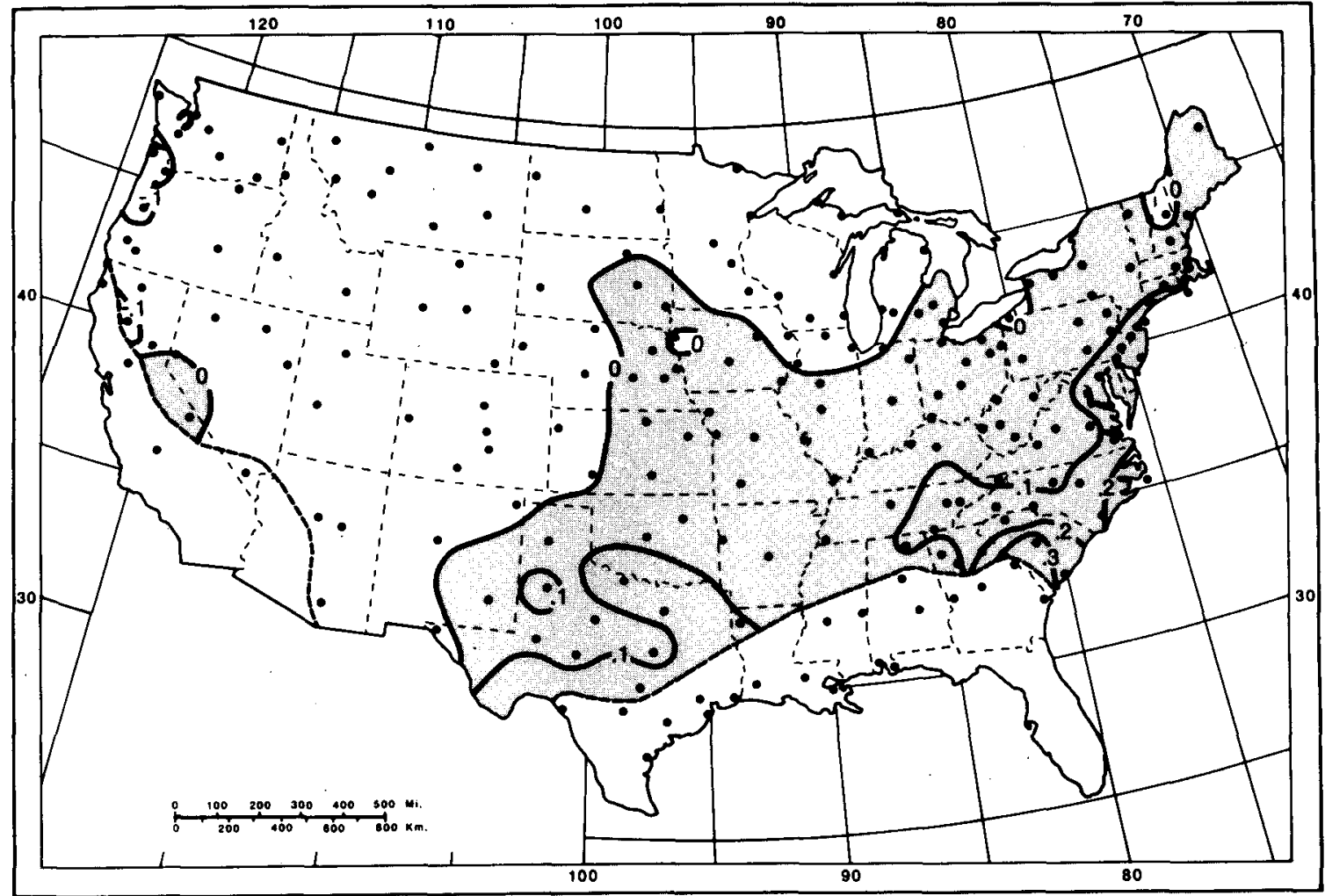

FIG. 14. As in Fig. 10, except for February.

reach their highest frequency and intensity in the continental interior in January (Zishka and Smith, 1980); corresponding negative deviations are indicative of the increased advection of cold dry air into the region.

In the western United States, the mean position of the jet continues its southward migration (Riehl et al., 1954). Although the normal circulation pattern is characterized by a high frequency of mean monthly ridge lines stretching from the Canadian Rockies southwestward into the eastern Pacific (Stark, 1965), synoptic studies (Jorgensen et al., 1967; Younkin, 1968) suggest that snowfalls are associated with deep troughs that tap moisture from the Pacific. Thus, the positive snowfall deviations in the West are produced by a relatively small number of individual storms associated with nonmodal circulation patterns.

\section{d. Late winter (February and March)}

The February pattern (Fig. 14) of snowfall deviations is much less complex than January, with almost onehalf of the conterminous United States exhibiting deviations below the national composite. Negative deviations extend throughout the mountainous western United States, across the Great Plains, and into the western Great Lakes region. Negative deviations in the Great Lakes area suggest a significant reduction in lakeeffect snowfall mechanisms during the late winter pe- riod as ice cover reaches its maximum extent on the Great Lakes. The positive deviations across the Southern Plains are a continuation of the January pattern and are indicative of the location's short snowfall season. Large positive deviations extend along the Atlantic Coast from North Carolina up to southern New England. These high values are suggestive of heavy snowfalls associated with strong "nor'easter" storms, such as the well-documented "Presidents' Day Snowstorm" of 18-19 February 1979 (Bosart, 1981), which tend to have their greatest frequency during this part of the winter season.

Upper-level flow patterns for February have a similar climatology to those of the previous month; ridge lines are characteristic of the eastern Pacific and western North America, whereas trough axes stretch southward from the Great Lakes to the southern Mississippi Valley (Stark, 1965). Likewise, the area of the circumpolar vortex remains at, or near, its seasonal maximum, with associated surface storm tracks originating, in some cases, in subtropical latitudes (Klein, 1957; Whittaker and Horn, 1981). Disturbances that migrate northeastward from the southcentral United States and/or the Gulf Coastal states usually intensify in the strong baroclinic zone that characterizes the lower and middle layers of the troposphere near the east coast-Gulf Stream boundary (Colucci, 1976). In many cases, these storms receive additional energy and dynamic support 
in upper tropospheric layers from interactions with the subtropical jet stream (Reiter, 1963).

March snowfall deviations from the national composite (Fig. 15) have a large contiguous area of positive snowfall deviations that extends from the western Midwest through the central and northern Great Plains to southwestern sections of the Front Range of the Rocky Mountains. Due to circulation readjustments, strong polar anticyclones are now less prevalent in the interior of the conterminous United States. The northward movement and realignment of the primary storm track has allowed sufficient incursions of warm air across the south, thus limiting the occurrence of snowfall in the region. An area of positive deviations, although significantly smaller in size, remains along the East Coast. This concentration is most likely the result of intense (but infrequent) nor'easters which occur with declining frequency as the transition to spring continues.

Significant readjustments in the circulation are characteristic of the transition from winter to spring. As zonal wind speeds decline in response to a weakening equator-to-pole thermal gradient, ridge and trough features in the westerlies tend to reposition in an upstream location as the wavelength of Rossby waves declines. Stark (1965) suggested that eastern North American troughs have their lowest concentration in the transitional seasons of March and October.
Studies using the index cycle concept (Namias, 1950) corroborated these changes; Chang (1972) suggested that the primary index cycle of the winter season occurs in the period from February to March. With these changes in the longitudinal position of longwave features, troughs occur with greater frequency in the western United States. For the midcontinent, southwesterly flow aloft favors low-level moisture advection from the Gulf of Mexico and an intensification of Colorado cyclones. The prospect for heavy snowfall events returns in earnest to the central United States.

\section{e. Spring (April and May)}

Positive deviations from the national composite for the months of April (Fig. 16) and May (Fig. 17) are located in the western High Plains and Rocky Mountains. Smaller areas of positive deviations also exist across the upper Great Lakes and at high elevations in northern New England. Both of these areas can have subfreezing temperatures at this time of year, with some of the precipitation occurring in the form of snow.

Throughout the months of April and May, circulation readjustments continue. Reitan (1974) has demonstrated that the southern Rocky Mountains become a preferred area for cyclogenesis and maps of monthly mean geopotential heights (Lahey et al., 1958) support this observation. During the spring, cyclonic flow de-

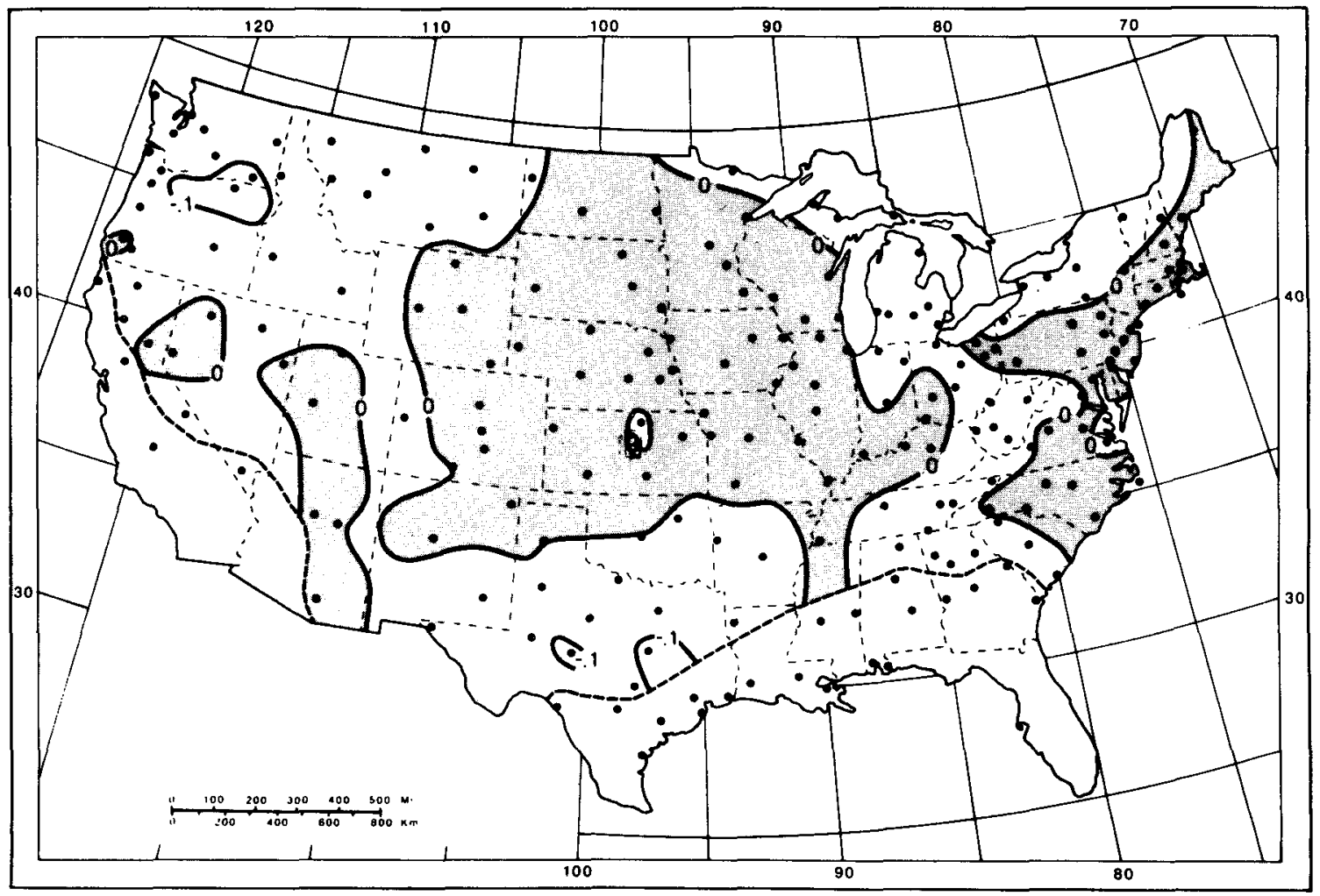

FIG. 15. As in Fig. 10, except for March. 


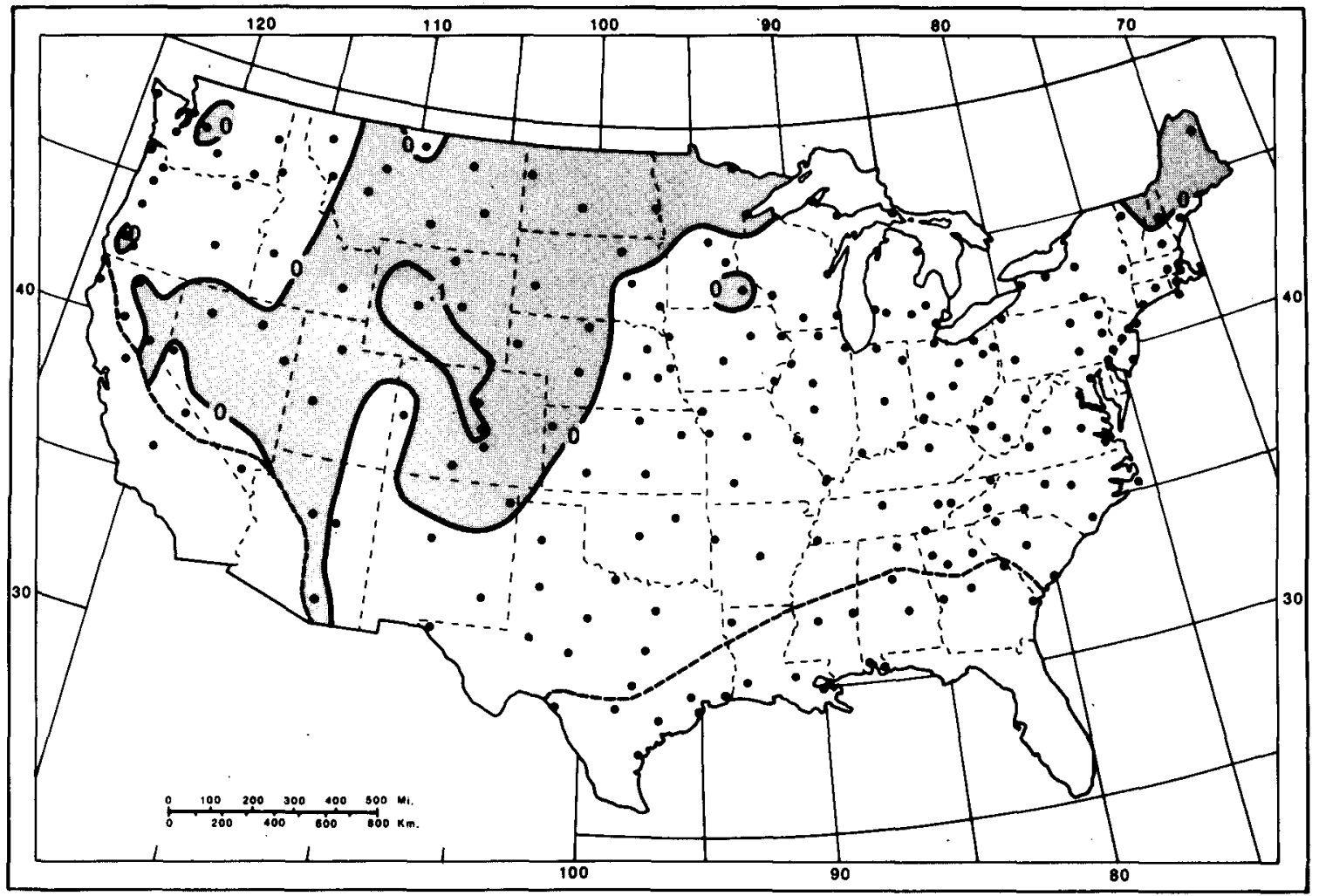

FIG. 16. As in Fig. 10, except for April.

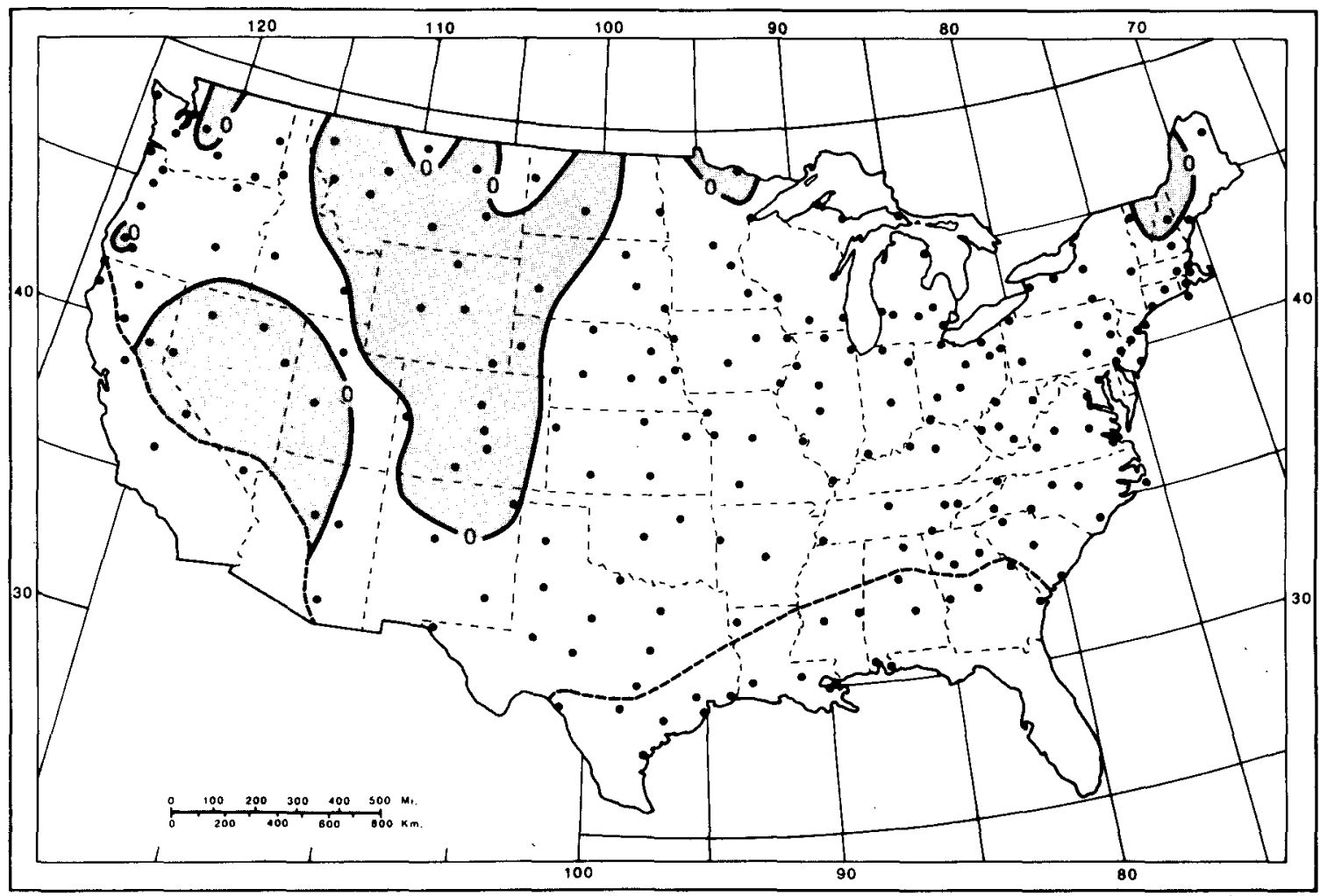

FIG. 17. As in Fig. 10, except for May. 
velops over the southern Rocky Mountains in an area that has a climatic tendency for anticyclonic flow during the rest of the year. O'Connor (1964) presented additional evidence to support the relatively unique character of the spring season circulation; monthly maps of the positions of 5-day, $700 \mathrm{mb}$ low centers show a seasonal tendency for cyclonic events in the western United States. During this period, there is also a tendency for temperature persistence in the intermountain West, and it has been suggested that the presence or absence of snow cover is one factor that pertains to this phenomenon (Dickson, 1967).

For areas in the western High Plains and the Rocky Mountains, April and May snowfalls are usually produced by upper-level disturbances moving through long wave troughs located over the western United States. Fawcett and Saylor (1966) have provided a synoptic climatology for Colorado cyclogenic events, and Djurić and Ladwig (1983) have demonstrated the relative importance of the low-level jet and its associated moisture advection from the western Gulf of Mexico as a major provider of additional energy for cyclone development. As in autumn, snowfall from upslope precipitation mechanisms occurs in the High Plains and along the Front Range of the Rockies (Laird and Dickey, 1953; Boatman and Reinking, 1984). The 16-17 May 1983 blizzard, which affected the Front Range and northeastern Colorado (NOAA, 1983), provides an example of this type of late season snowstorm. Below normal $700 \mathrm{mb}$ height anomalies over the contiguous United States persisted from April to May 1983; a cyclonic circulation aloft resulted in heavy snowfalls and above normal precipitation across the Rockies during May (Chen, 1983). These spring storms and associated snowfall events usually mark the end of the United States snowfall season.

\section{Summary and conclusions}

Although economic and political concerns tend to be linked to short-term meteorological events, past studies of frozen precipitation have concentrated on snow cover and depth, variables that incorporate temporal persistence. This investigation has presented a basic climatology of snowfall events using mean monthly snowfall totals for the conterminous United States, emphasizing statistical and geographical analyses. Statistical measures of the length of the snowfall season suggest that the effects of latitude, elevation, and continentality are influential in determining the length of the snow season.

Harmonic analysis indicates a snowfall maximum across the conterminous United States in February; the Great Lakes area and the Pacific Northwest have earlier snowfall maxima. Individual station snowfall distributions that have a large amount of their variance accounted for by a second harmonic have either a generally short snowfall season (e.g., the southeastern
United States), a long snowfall season with a tendency toward a bimodal profile (e.g., stations in Wyoming), or lake-effect enhanced, early to midwinter snowfall totals (e.g., areas to the lee of the Great Lakes).

Analysis of intraseasonal variability was facilitated by calculating the deviation of monthly percentages of the annual total for individual stations from a national composite. The geographical patterns of these deviations are closely linked to seasonal upper-level circulation patterns and the synoptics of storm events. In autumn, the start of the annual snowfall season is marked by snow events that affect areas in the northern High Plains and high-elevation areas across the northern tier of states. As the season progresses and the circumpolar vortex expands, snowfalls spread farther southward and eastward; in addition, areas around the Great Lakes are strongly influenced by lake-effect storms. By midwinter, snowfall areas and the upperlevel westerlies are at their maximum extent. Nor'easter storms, tracking up the Atlantic Coast, give areas along the eastern seaboard a relatively high proportion of their annual snow total. The transition to spring is accompanied by a shift to more frequent troughs in the central and western United States and storms moving along the Colorado storm track. As the annual snowfall season draws to a close, late season events are usually restricted to the northern High Plains and high elevation areas in northern latitudes.

Acknowledgments. All three authors were members of the Climatology Program, Department of Geography, University of Nebraska-Lincoln for the research and initial formulation of the text. University support, including cartography, is greatly appreciated. The computer program used in this investigation for harmonic analysis of a time series was written for the Climatology Program, Department of Geography, University of Nebraska-Lincoln by Dr. Robert C. Balling.

\section{REFERENCES}

Baldwin, J. L., 1974: Climates of the United States. U.S. Department of Commerce, Washington, DC, 113 pp.

Balling, R. C., and R. S. Cerveny, 1983: Spatial and temporal variations in long-term normal percent possible solar radiation levels in the United States. J. Climate Appl. Meteor., 22, 1726-1732.

- , and - 1984: Analysis of time and space variations in longterm monthly averaged wind speeds in the United States. Wind Eng., 8, 1-8.

Boatman, J. F., and R. F. Reinking, 1984: Synoptic and mesoscale circulations and precipitation mechanisms in shallow upslope storms over the western High Plains. Mon. Wea. Rev., 112, 17251744.

Bosart, L. F., 1981: The Presidents' Day snowstorm of 18-19 February 1979: A subsynoptic-scale event. Mon. Wea. Rev., 109, 15421566.

Brooks, C. E. P., and N. Carruthers, 1953: Handbook of Statistical Methods in Meteorology. HMSO, London, $412 \mathrm{pp}$.

Browne, R. F., and R. J. Younkin, 1970: Some relationships between 850-millibar lows and heavy snow occurrences over the central and eastern United States. Mon. Wea. Rev., 98, 399-401.

Chang, J., 1972: Atmospheric Circulation Systems and Climates. Oriental Publ., 328 pp. 
Changnon, S. A., and D. Jones, 1972: Review of the influences of the Great Lakes on weather. Wat. Resour. Res., 8, 360-371.

Chen, W. Y., 1983: The climate of Spring 1983-A season of persistent global anomalies associated with $\mathrm{El}$ Niño. Mon. Wea. Rev., 111, 2371-2384.

Colucci, S. J., 1976: Winter cyclone frequencies over the eastern United States and adjacent western Atlantic, 1964-73. Bull. Amer. Meteor. Soc., 57, 548-553.

Craddock, J. M., 1956: The representation of the annual temperature variation over Central and Northern Europe by a two-term harmonic form. Quart. J. Roy. Meteor. Soc., 83, 275-288.

Dewey, K. F., 1979: An objective forecast method developed for Lake Ontario induced snowfall systems. J. Appl. Meteor., 18, 787-793.

- , and R. Heim, Jr., 1982: A digital archive of Northern Hemisphere snow cover, November 1966 through December 1980. Bull. Amer. Meteor. Soc., 63, 1132-1141.

Dickson, R. R., 1967: The climatological relationship between temperatures of successive months in the United States. J. Appl. Meteor., 6, 31-38.

Djurić, D., and D. S. Ladwig, 1983: Southerly low-level jet in the winter cyclones of the Southwestern Great Plains. Mon. Wea. Rev., 111, 2275-2281.

Eichenlaub, V. L., 1970: Lake-effect snowfall to the lee of the Great Lakes: Its role in Michigan. Bull. Amer. Meteor. Soc., 51, 403412.

Falconer, R. L., L. Lansing and R. Sykes, 1964: Studies of the weather phenomena to the lee of the eastern Great Lakes. Weatherwise, 17, 256-261.

Fawcett, E. B., and H. K. Saylor, 1965: A study of the distribution of weather accompanying Colorado cyclogenesis. Mon. Wea. Rev., 93, 359-367.

Fitzpatrick, E. A., D. Hart and H. C. Brookfield, 1966: Rainfall seasonality in the tropical Southwest Pacific. Erkunde, 20, 181194.

Goree, P. A., and R. J. Younkin, 1966: Synoptic climatology of heavy snowfall over the central and eastern United States. Mon. Wea. Rev., 94, 663-668.

Harman, J. R., 1982: The normal summer-autumn precipitation decline in the northcentral United States. Phy. Geog., 3, 1-16.

$\longrightarrow$, R. Rosen and W. Corcoran, 1980: "Winter cyclones and circulation patterns on the western Great Lakes. Phy. Geog., 1, 28-41.

Heim, R., Jr., and K. F. Dewey, 1984: Circulation patterns and temperature fields associated with extensive snow cover on the North American continent. Phys. Geog., 4, 66-85.

Hjelmfelt, M. R., and R. R. Braham, 1983: Numerical simulation of the airflow over Lake Michigan for a major lake-effect snow event. Mon. Wea. Rev., 111, 205-219.

Horn, L. H., and R. A. Bryson, 1960: Harmonic analysis of the annual march of precipitation over the United States. Annals, Assoc. Amer. Geog., 50, 157-171.

Jiusto, J. E., and M. Kaplan, 1972: Snowfall from lake-effect storms. Mon. Wea. Rev., 100, 62-66.

Jorgensen, D. L., W. H. Klein and A. F. Korte, 1967: A synoptic climatology of winter precipitation from 700 -mb lows for intermountain areas of the West. J. Appl. Meteor., 6, 782-790.

Klein, W. H., 1948: Winter precipitation as related to the $700-\mathrm{mb}$ circulation. Bull. Amer. Meteor. Soc., 29, 439-453.

- 1957: Principal Tracks and Mean Frequencies of Cyclones and Anticyclones in the Northern Hemisphere. Research Pap. No. 40 , U.S. Weather Bureau, Washington, DC, $60 \mathrm{pp}$.

- 1963: Specification of precipitation from the 700-millibar circulation. Mon. Wea. Rev., 91, 527-536.
Lahey, J. F., R. A. Bryson, E. W. Wahl, L. H. Horn and V. D. Henderson, 1958: Atlas of $500 \mathrm{mb}$ Wind Characteristics for the Northern Hemisphere. University of Wisconsin Press.

Laird, H. B., and W. W. Dickey, 1953: Forecasting rain or snow at Denver, Colorado, September through November. Bull. Amer. Meteor. Soc., 34, 287-292.

Lamb, H. H., 1972: Climate: Present, Past and Future. Vol. 1, Methuen and Co., 613 pp.

Namias, J., 1950: The index cycle and its role in the general circulation. J. Meteor., 7, 130-139.

- 1953: Thirty day forecasting: A review of a ten year experiment. Meteor. Monogr., 6, 1-83.

- 1960: Snowfall over the eastern United States: Factors leading to its monthly and seasonal variations. Weatherwise, 13, 238247.

- 1985: Some empirical evidence for the influence of snow cover on temperature and precipitation. Mon. Wea. Rev., 113, 15421553.

NOAA, 1981: Comparative Climatic Data For the United States Through 1980. National Climatic Center, Asheville, NC, 94 pp. , 1983: Storm Data, 25(5), p. 20.

O'Connor, J. F., 1964: Hemispheric distribution of 5-day mean 700mb circulation centers. Mon. Wea. Rev., 92, 303-315.

Oliver, J. E., 1980: Monthly precipitation distribution: A comparative index. Pro. Geog., 32, 300-309.

Potter, J. G., 1965: Snow cover. Climatological Studies, No. 3, Meteorological Branch, Department of Transport, Canada, $69 \mathrm{pp}$.

Reitan, C. H., 1974: Frequencies of cyclones and cyclogenesis for North America, 1951-70. Mon. Wea. Rev., 102, 861-868.

Reiter, E. R., 1963: Jet-Stream Meteorology. University of Chicago Press, $515 \mathrm{pp}$.

Richter, G. D., 1960: Geografiya Snezhnogo Pokrova (Geography of Snow Cover). Akademii Nauk SSSR, Moscow.

Riehl, H., M. A. Alaka, C. L. Jordan and R. J. Renard, 1954: The Jet Stream. Meteor. Monogr., 2(7), 1-100.

Robock, A., 1980: The seasonal cycle of snow cover, sea ice and surface albedo. Mon. Wea. Rev., 108, 267-270.

Rooney, J. F., Jr., 1967: The urban snow hazard in the United States: An appraisal of disruption. Geog. Rev., 57, 538-559.

Stark, L. P., 1965: Positions of mean monthly troughs and ridges in the Northern Hemisphere. Mon. Wea. Rev., 93, 705-720.

Strommen, N. D., and J. R. Harman, 1978: Seasonally changing patterns of lake-effect snowfall in western Lower Michigan. Mon. Wea. Rev., 108, 503-509.

Wahl, E. B., 1954: A weather singularity over the U.S. in October. Bull. Amer. Meteor. Soc., 35, 351-356.

Walsh, J. E., D. R. Tucek and M. R. Peterson, 1982: Seasonal snow cover and short-term climatic fluctuations over the United States. Mon. Wea. Rev., 110, 1474-1485.

Whittaker, L. M., and L. H. Horn, 1981: Geographical and seasonal distribution of North American cyclogenesis, 1958-77. Mon. Wea. Rev., 109, 2312-2322.

Wiesnet, D. R., and M. Matson, 1979: NOAA satellite derived continental snow cover data base. Glaciological Data, Report GD6: Snow Cover, World Data Center-A for Glaciology (Snow and Ice), Boulder, 3-8.

Younkin, R. J., 1968: Circulation patterns associated with heavy snowfall over the western United States. Mon. Wea. Rev., 96, 851-853.

Zishka, K. M., and P. J. Smith, 1980: The climatology of cyclones and anticyclones over North America and surrounding environs for January and July, 1950-77. Mon. Wea. Rev., 108, 387-401. 